\title{
Bacillus subtilis single-stranded DNA-binding protein SsbA is phosphorylated at threonine 38 by the serine/threonine kinase YabT
}

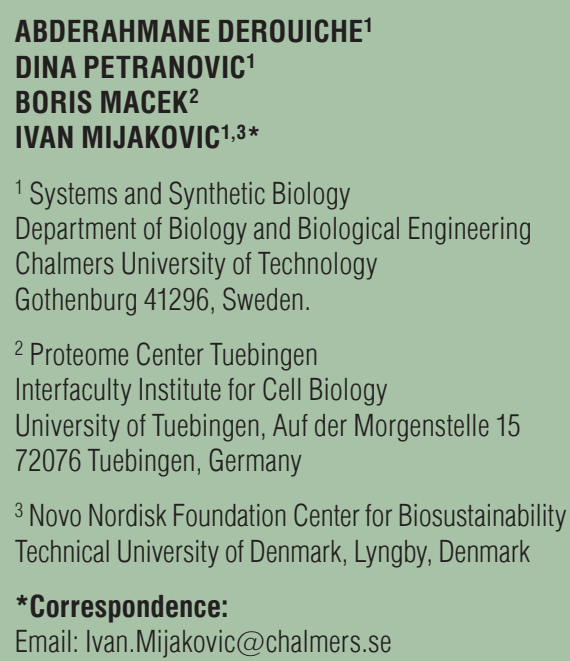

Keywords: protein kinase; protein phosphorylation; DNA metabolism cooperative binding; mass spectrometry
Received October 03, 2016.

Revised November 28, 2016.

Accepted November 29, 2016

\begin{abstract}
Background and purpose: Single-stranded DNA-binding proteins participate in all stages of DNA metabolism that involve single-stranded $D N A$, from replication, recombination, repair of DNA damage, to natural competence in species such as Bacillus subtilis. B. subtilis single-stranded DNA-binding proteins have previously been found to be phosphorylated on tyrosine and arginine residues. While tyrosine phosphorylation was shown to enhance the DNA-binding properties of SsbA, arginine phosphorylation was not functionally characterized.
\end{abstract}

Materials and methods: We used mass spectrometry analysis to detect phosphorylation of SsbA purified from B. subtilis cells. The detected phosphorylation site was assessed for its influence on DNA-binding in vitro, using electrophoretic mobility shift assays. The ability of B. subtilis serinel threonine kinases to phosphorylate SsbA was assessed using in vitro phosphorylation assays.

Results: In addition to the known tyrosine phosphorylation of SsbA on tyrosine 82, we identified a new phosphorylation site: threonine 38. The in vitro assays demonstrated that $S s b A$ is preferentially phosphorylated by the B. subtilis Hanks-type kinase YabT, and phosphorylation of threonine 38 leads to enhanced cooperative binding to DNA.

Conclusions: Our findings contribute to the emerging picture that bacterial proteins, exemplified here by SsbA, undergo phosphorylation at multiple residues. This results in a complex regulation of cellular functions, and suggests that the complexity of the bacterial cellular regulation may be underestimated.

\section{INTRODUCTION}

$\mathrm{T}$ he model Gram-positive bacterium Bacillus subtilis possesses two single-stranded DNA-binding proteins, SsbA and SsbB (1). Physiological roles of both these proteins have been under extensive investigation for over a decade, and they are currently known to participate in DNA replication (2), recombination (3), damage repair (4) and the process of transformation of the B. subtilis chromosome in the state of natural competence (5). We have previously reported that B. subtilis SsbA and SsbB can undergo phosphorylation at tyrosine residues, and this phosphorylation is catalyzed by the B. subtilis BY-kinase PtkA (6). In the case of SsbA, it was determined that PtkA-dependent phosphorylation occurs on the residue tyrosine 82 . This residue belongs to the $\mathrm{N}$-terminal region of the protein, known to be involved directly in DNA 
binding. Phosphorylation of tyrosine 82 was shown to lead to enhanced binding of SsbA to single-stranded DNA (6). SsbA phosphorylation in vivo was shown to diminish during the DNA-damage response and we speculated that it may be involved in the repair mechanisms (6). Soon thereafter, we demonstrated a pronounced cell cycle phenotype of the $\Delta p t k A$ strain, which could also be related to the loss of phosphorylation of SsbA (7). More recently, phosphorylation of $\mathrm{SsbB}$ on an arginine residue was detected in a global phosphoproteome study (8). The physiological effect of arginine phosphorylation on SsbB was not further investigated, but it was shown that the $B$. subtilis protein-arginine kinase $\mathrm{Mcs} B$ can phosphorylate it in vitro (8). Evidence of phosphorylation of singlestranded DNA-binding proteins on tyrosine residues was obtained also from studies on other bacteria: Escherichia coli and Streptomyces coelicolor $(6,9)$.

It is a common occurrence that a single BY-kinase (10) or bacterial protein-arginine kinase (8) can phosphorylate a pool of different cellular proteins, and by doing so simultaneously regulate or coordinate different cellular processes. The members of another family of protein kinases present in bacteria, the Hanks-type serine/threonine kinases, also typically display this "promiscuous” behavior towards protein substrates. In $B$. subtilis, three such Hanks-type kinases have been described: PrkC (11), YabT (12) and PrkD (13). All of them have been shown to phosphorylate different cellular substrates. Interestingly, significant phosphorylation-based cross-talk has been demonstrated between $B$. subtilis BY-kinases and Hanks-type kinases (14). Kinases from these two different families phosphorylate each other at key regulatory residues, and thus have the capacity to create signal interference or overlap between the two regulatory networks. Phosphoproteome studies performed on different bacterial species indicate that the overlap between BY-kinase and Hanks-type serine/threonine kinases also exists on the substrate level, with a significant number of bacterial proteins phosphorylated by both types of kinases (15).

In this study, we report an example of a bacterial protein that undergoes phosphorylation on tyrosine, arginine and threonine residues. In addition to the known phosphorylation events taking place on tyrosine and arginine, we demonstrate that the B. subtilis SsbA gets phosphorylated at threonine 38 in vivo. In vitro, this phosphorylation is catalyzed most efficiently by the Hanks-type B. subtilis kinase YabT. The consequence of phosphorylation is the enhanced cooperativity of SsbA binding to single-stranded DNA.

\section{MATERIALS AND METHODS}

\section{Bacterial strains and growth conditions}

The B. subtilis strain SPSSBHT (6) was used to synthesize the 6xHis-tagged SsbA as previously described (6).
E. coli M15 carrying pREP4-GroESL was used for overexpression of proteins from recombinant $\mathrm{PQE}-30$ vectors as previously described (16). All strains were grown in Luria-Bertani (LB) medium with shaking, at $37^{\circ} \mathrm{C}$. When appropriate, ampicillin $(100 \mu \mathrm{g} / \mathrm{ml})$ and kanamycin $(25 \mu \mathrm{g} / \mathrm{ml})$ for $E$. coli and neomycin $(5 \mu \mathrm{g} / \mathrm{ml})$ for $B$. subtilis were supplied to the medium.

\section{Construction of SsbA T38D}

The $s s b A$ codon for threonine 38 was replaced by a codon for aspartate, using site-specific primer-directed PCR mutagenesis, as described previously (6). The resulting PCR product was integrated in the $\mathrm{pQE}-30$ vector and the absence of any unwanted mutations in the $s s b A$ coding region was verified by sequencing.

\section{Synthesis and purification of tagged proteins}

All the recombinant proteins, SsbA, SsbAT38D, SsbAY82E, PrkC, PrkD and YabT were synthesized as 6xHis N-terminal fusion in E.coli M15 harboring pREP4GroESL. The cultures were grown with shaking at 200 $\mathrm{rpm}$ at $37^{\circ} \mathrm{C}$ to $\mathrm{OD}_{600} 0.5$. The protein expression was induced by adding $1 \mathrm{mM}$ of Isopropyl $\beta$-D- 1 thiogalactopyranoside, and then the cells were grown for additional 3 hours. The 6xHis-tagged proteins were purified using Ni-NTA columns and the standard protocol from the supplier (Qiagen). All proteins aliquots were stored at $-80^{\circ} \mathrm{C}$ in a glycerol containing buffer $(10 \%)$ composed of $50 \mathrm{mM}$ Tris-Cl pH 7.5 and $100 \mathrm{mM} \mathrm{NaCl}$. For purification of 6xHis tagged SsbA from B. subtilis SPSSBHT, $10 \mathrm{mM}$ sodium pyrophosphate was added to the cell lysate to inhibit the phosphatase activity, before the standard purification on the Ni-NTA column.

\section{Determination of phosphorylation site by mass spectrometry}

Determination of the phosphorylation site on 6xHistagged SsbA was performed essentially as described previously (6). Briefly, the purified protein $(50 \mathrm{mg}$ ) was dissolved in $8 \mathrm{M}$ urea, reduced (DTT), carboxyamidomethylated (iodoacetamide) and digested with trypsin. The digest was fractionated using into 10 fractions on a Source

15RPC ST 4.6/100 column (Amersham Pharmacia Biotech) and each $1 \mathrm{ml}$ fraction was subjected to phosphopeptide enrichment using $50 \mu \mathrm{l}$ PHOS-Select ${ }^{\mathrm{TM}}$ IMAC beads (Sigma). The phosphorylation of peptides was analyzed on an LTQ-FT mass spectrometer (Thermo Electron) coupled to an 1100 nano-HPLC system (Agilent Technologies). Peptides were separated on an inhouse made nano-C18 HPLC column (ID $75 \mu \mathrm{m} \times 15 \mathrm{~cm}$ ) and ionized by electrospray ionization. The mass spectra were acquired in the positive ion mode and MS acquisition cycles consisted of a full scan in the FT ICR cell, 
followed by MS/MS scans of the five most intense ions in the linear ion trap. Resulting mass spectra were searched against the NCBInr database using the Mascot search engine (Matrix Science).

\section{In vitro phosphorylation assay}

The phosphorylation assay was performed as described previously (16). A $40 \mu \mathrm{l}$ reaction mix contained $1 \mu \mathrm{M}$ serine /threonine kinase (either YabT, PrkC or PrkD), $5 \mu \mathrm{M}$ SsbA, $50 \mu \mathrm{M}$ ATP $\left[\gamma_{-}{ }^{32} \mathrm{P}\right]\left(20 \mu \mathrm{Ci} / \mathrm{mmol}\right.$ of $\left.\gamma_{-}{ }^{32} \mathrm{P}\right)$, $1 \mathrm{mM} \mathrm{MgCl}_{2}$ and $100 \mathrm{mM}$ Tris- $\mathrm{HCl}$ at $\mathrm{pH}$ 7.5. The proteins were incubated with radioactive ATP for 1 hour at $37^{\circ} \mathrm{C}$. The reactions were stopped by the addition of the SDS-PAGE buffer and heating at $100^{\circ} \mathrm{C}$ for 5 minutes.
The protein samples were separated by electrophoresis on $12 \%$ polyacrylamide SDS gels. To reduce the background, the gel was boiled in $0.5 \mathrm{M} \mathrm{HCl}$ for 10 minutes. Transient staining with Coomassie Blue was used to identify protein bands. The gels were dried overnight, and the signals were visualized with the FUJI phosphoimager. The experiment was repeated three times with proteins purified independently. One representative experiment is shown.

\section{Electrophoretic mobility shift assay}

The DNA binding assays were performed with 20-, 40 - and 80 bp long single stranded DNA fragments with random sequence. Different ratios (indicated in the figure
A

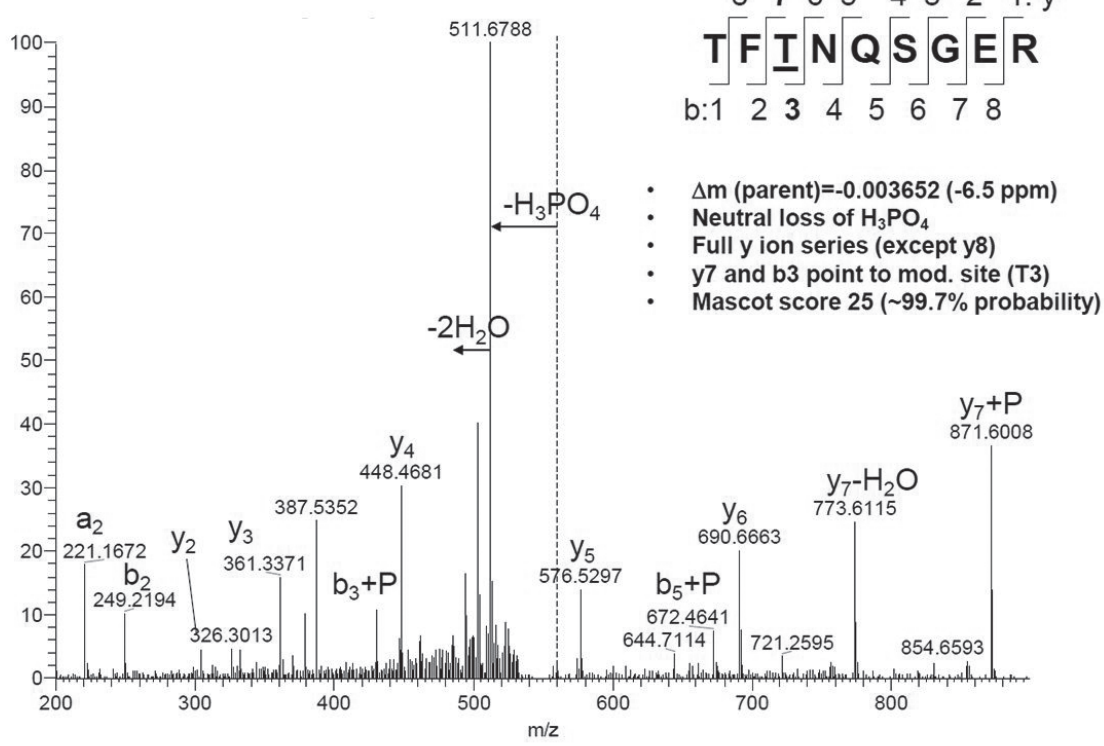

B

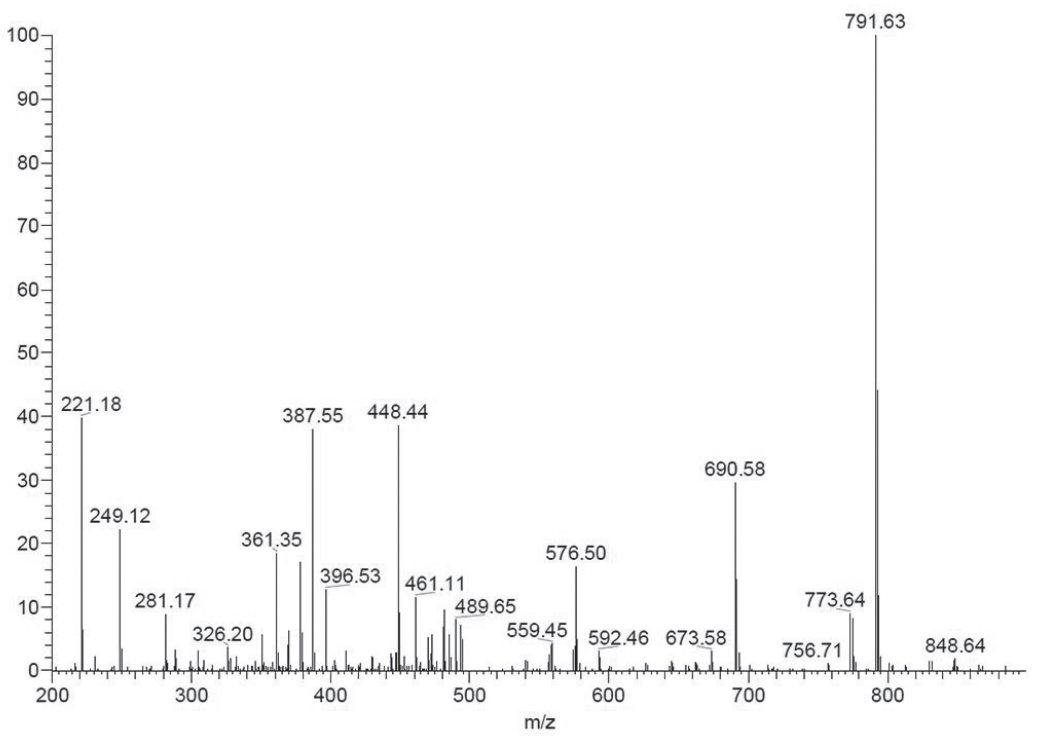

$\begin{array}{llllllll}8 & 7 & 6 & 5 & 4 & 3 & 2 & 1: y\end{array}$

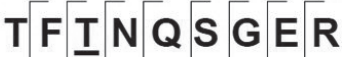
$: \begin{array}{lllllllll}1 & 2 & 3 & 4 & 5 & 6 & 7 & 8\end{array}$

Neutral loss of $\mathrm{H}_{3} \mathrm{PO}_{4}$

Full y ion series (except y8)

y7 and b3 point to mod. site (T3)

lity)
Figure 1. Identification of threonine 38 as the phosphorylated residue in $B$. subtilis SsbA. (A) The MS/MS spectrum of the doubly-charged precursor ion at $\mathrm{m} / \mathrm{z} 560.225$, corresponding to the B. subtilis SsbA peptide TFTNQSGER (theoretical monoisotopic mass 560.227) with one phosphorylated residue. The fragmentation pattern is consistent with phosphorylation on the residue Thr38. (B) The MS/MS spectrum of the precursor ion at the $\mathrm{m} / \mathrm{z}$ ratio of 520.240 , corresponding to the non-phosphorylated peptide. 
legend) of the single-stranded DNA and SsbA, SsbAT38D, SsbAY82E were mixed in $100 \mathrm{mM}$ Tris- $\mathrm{HCl}$, $\mathrm{pH} 7.5$, and incubated for $20 \mathrm{~min}$ at room temperature. After the incubation, the reactions were analyzed by electrophoresis, under the following conditions: $2 \mathrm{~h}$ migration at $2.5 \mathrm{~V} / \mathrm{cm}$ in 0.5 Tris-acetate-EDTA, using an $8 \%$ polyacrylamide gel without SDS. After the migration, the gels were incubated for 20 minutes with shaking in $50 \mathrm{ml}$ of Tris-Glycine buffer supplemented with $1 \mu \mathrm{g} / \mathrm{ml}$ of ethidium bromide to visualize DNA. The experiment was repeated three times with proteins purified independently. One representative experiment is shown.

\section{RESULTS AND DISCUSSION}

\section{SsbA is phosphorylated at threonine 38 in vivo and this phosphorylation leads to enhanced cooperative binding to single-stranded DNA}

In an attempt to detect additional phosphorylation sites on the $B$. subtilis SsbA, we have purified the 6xHistagged protein directly from $B$. subtilis, and subjected it to a mass spectrometry analysis. In addition to the residue tyrosine 82 , which was detected previously (6), we detected an unambiguous phosphorylation signal on the residue threonine 38 , situated at the third position in the tryptic peptide TFTNQSGER (Figure 1A). Identification was confirmed by comparison the MS/MS spectrum of the non-phosphorylated peptide (Figure 1B). In order to study the effect on phosphorylation of the residue threonine 38 on the activity of SsbA, we constructed a phospho-mimetic version of the protein, SsbA T38D. SsbAY38D carries a negatively charged aspartate residue in place of threonine 38, thus mimicking the phosphoryla- tion state of SsbA (17). SsbA, like all bacterial singlestranded DNA proteins, forms tetramers which bind single-stranded DNA $(6,18)$. Each tetramer binds 25-30 base pairs (19), and longer single-stranded DNA molecules can bind several Ssb proteins. We therefore compared the binding of SsbA and SsbA T38D to a 40-base pair (Figure 2A) and a 80-base pair single stranded DNA fragment (Figure 2B), each with a completely random sequence. In each case the SsbA-DNA molar ratio was varied from 25:1 to 100:1. SsbA and SsbA T38D exhibited a similar binding profile with the 40-base pair fragment, in which case typically one Ssb tetramer binds per fragment. This suggests that the affinity of the SsbA tetramer for single-stranded DNA is not significantly affected by phosphorylation of the residue threonine 38. By contrast, with the 80-base pair DNA fragment, there was a significant difference in the binding profiles. For SsbA, for the majority of protein: DNA ratios, the dominant shifted band was the lower one, corresponding to one bound tetramer per fragment. SsbA T38D had a much higher propensity to form the higher molecular weight complex, with two SsbA tetramers per fragment, indicating that cooperativity of binding was enhanced by the T38D mutation. The effect of phosphorylation of SsbA threonine 38 would therefore seem to be quite different from the effect of phosphorylation of tyrosine 82 . While phosphorylation of the tyrosine 82 dramatically increased the SsbA affinity for single-stranded DNA (6), phosphorylation of the threonine 38 enhanced the capacity of SsbA tetramers to attach adjacently to a single-stranded DNA substrate. It was recently demonstrated that the disordered C-terminal region of bacterial Ssb proteins collapses towards the tetramer upon DNA-binding (20), thus leading to a more compact structure. It is tempting to speculate that phosphorylation of threonine 38 could
A

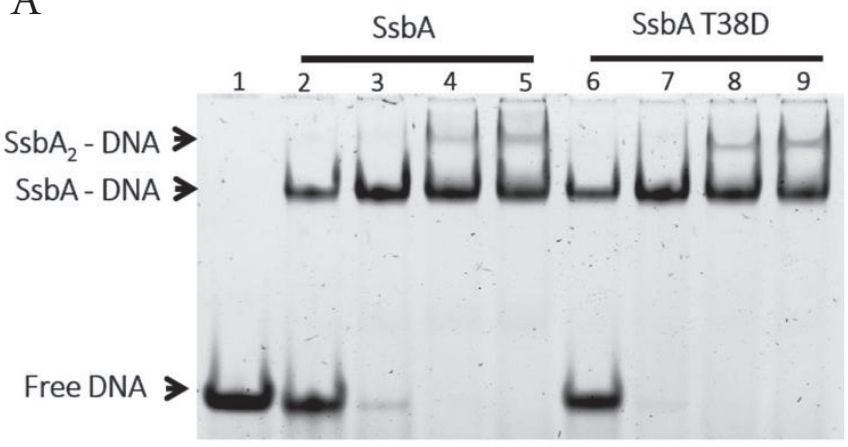

B

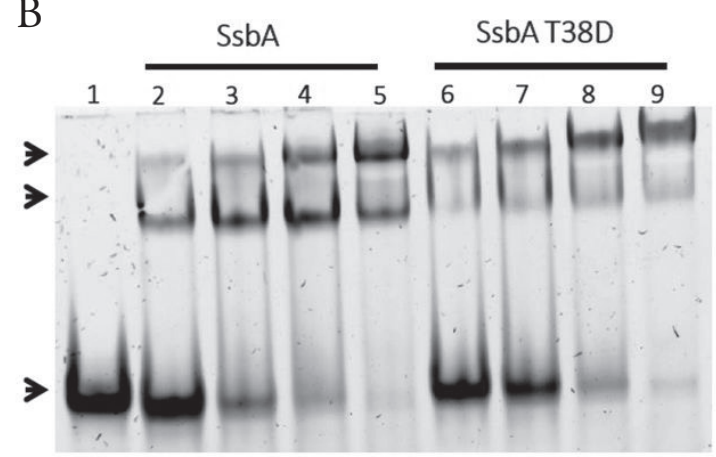

Figure 2. SsbA T38D exhibits enhanced cooperative binding to single-stranded DNA. Electrophoretic mobility shift assays with purified SsbA and SsbA T38D, and random sequence single-stranded DNA fragments. 10 pmol of DNA target were used in all lanes. A 40-base pairs $D N A$ fragment $(A)$ and an 80-base pairs DNA fragment (B) were tested. In both gels the lane 1 corresponds to free DNA control, with no added protein. The presence of either SsbA or SsbA T38D is indicated above each lane. In lanes 2-5 and 6-9, the final concentration of the protein was 250, 500, 750 and 1000 pmol, respectively. This corresponds to molar ratios of protein to DNA of of 1:25, 1:50, 1:75 and 1:100). The samples were separated by electrophoresis and DNA was visualized after ethidium bromide staining. The arrows indicate the signal of free $D N A$, the SsbA-DNA complex (one tetramer per DNA fragment), and the SsbA-DNA complex (2 tetramers per DNA fragment). A representative result from three replicates with independently purified proteins is shown. 
Figure 3. YabT phosphorylates SsbA. In vitro phosphorylation assay with purified B. subtilis Hanks-type kinases YabT, PrkC and PrkD $(1 \mu M)$, and the SsbA (5 $\mu M)$. The protein(s) present in the assay are indicated above each lane. Reactions were incubated for $60 \mathrm{~min}$ in the presence of $32 P$ $\gamma$-ATP, run on SDS-PAGE, and signals were revealed by autoradiography. The positon to which SsbA migrates on the gel is indicated by an arrow.

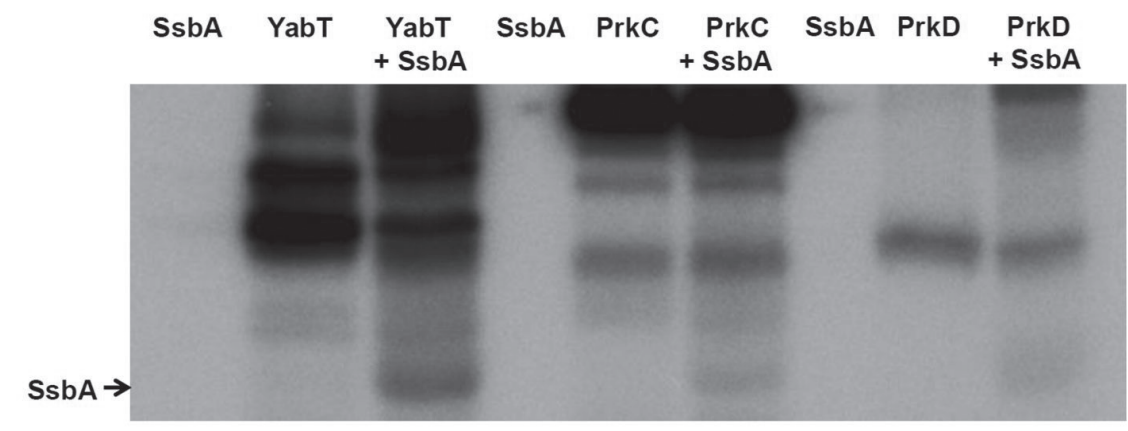

lead to a specific interaction with the C-terminal domains of adjacent SsbA monomers, and thereby aid the compacting process upon binding single-stranded DNA. This and other possible hypotheses regarding the phenotype of the T38D mutation will have to be verified experimentally.

\section{Hanks-type kinase YabT phosphorylates SsbA}

In $B$. subtilis, three Hanks-type serine/threonine kinases are known to exist: PrkC (11), YabT (12) and PrkD (13). All of these kinases are known to phosphorylate several different $B$. subtilis proteins, and were thus potential candidates for phosphorylating SsbA on threonine. In order to assess their capacity to phosphorylate SsbA, we used an in vitro phosphorylation assay described previously (6). Purified kinases were individually incubated with SsbA, in the presence of ATP radioactively labelled at the gamma position. In this assay, kinases use the phosphate at the gamma position in the ATP to autophosphorylate, or phosphorylate protein substrates. This in vitro phosphorylation assay revealed that all three Hankstype serine-threonine kinases can phosphorylate SsbA to some extent (Figure 3). From the densitometry quantification of the phosphorylated SsbA bands, we concluded that PrkD is the least efficient kinase of SsbA (relative band intensity 11.235), followed by PrkC (relative band intensity 20.902), and YabY is the most efficient of the three (relative band intensity 68.544). We concluded that YabT is likely to be the main kinase responsible for phosphorylation of SsbA. Interestingly, we have previously shown that YabT phosphorylates the general recombinase RecA of $B$. subtilis, at the residue serine 2 (12). Phosphorylation of RecA occurred mainly during early spore formation, and was required for RecA participation in checking chromosome integrity during sporulation. Specifically, YabTdependent phosphorylation enhanced the formation of transient RecA foci on the B. subtilis chromosome, and the absence of phosphorylation led to increased sensitivity to DNA damage. Our present results suggest that YabT also activates the loading of multiple tetramers of SsbA onto single-stranded DNA, by phosphorylating its residue threonine 38. It is plausible to presume that the formation of RecA foci and loading of SsbA tetramers are a part of the same mechanism involved in either sensing or repairing DNA damage. YabT, which is mainly expressed during sporulation (12), could be the key activator of RecA and SsbA for participating in this early sporulation check-point. To further explore this hypothesis, quantification of phosphorylation of SsbA and RecA should be performed in time dependent manner during early stages of sporulation, and correlated to YabT activity measured in vivo.

\section{CONCLUSION AND PERSPECTIVE}

Our present findings regarding phosphorylation of $B$. subtilis SsbA by the Hanks-type kinase YabT contribute to the emerging picture of a very complex signal transduction network in bacteria. It also strengthens the notion that there is as significant overlap between the tyrosineand serine/threonine-phosphorylation systems, both at the kinase cross-phosphorylation and the substrate phosphorylation level. Individual phosphorylation sites, such as the phospho-threonine 38 of SsbA usually represent an incremental contribution to the regulation of a complex physiological process. Given the known involvement of the kinase YabT in spore formation, the most likely role of SsbA phosphorylation at threonine 38 is to participate in the RecA-dependent chromosome integrity check (12). However, this will require further investigation, and the involvement in other stages of single-stranded DNA metabolism cannot be excluded at this stage.

Acknowledgments: This work was supported by grants from the Chalmers University of Technology, Vetenskapsradet (2015-05319) and the Novo Nordisk Foundation to IM.

\section{REFERENCES}

1. LINDNER C, NIJLAND R, VAN HARTSKAMP M, BRON S, HAMOEN LW, KUIPERS OP 2004 Differential expression of two paralogous genes of Bacillus subtilis encoding single-stranded DNA binding protein. J Bacteriol. 186:1097-1105.

https://doi.org/10.1128/JB.186.4.1097-1105.2004

2. COSTES A, LECOINTE F, MCGOVERN S, QUEVILLONCHERUEL S, POLARD P 2010 The C-terminal domain of the bacterial SSB protein acts as a DNA maintenance hub at active chromosome replication forks. PLoS Genet 6:e1001238.

https://doi.org/10.1371/journal.pgen.1001238 
3. YADAV T, CARRASCO B, MYERS AR, GEORGE NP, KECK JL, ALONSO JC 2012 Genetic recombination in Bacillus subtilis: a division of labor between two single-strand DNA-binding proteins. Nucleic Acids Res 40:5546-5559.

https://doi.org/10.1093/nar/gks173

4. LENHART JS, BRANDES ER, SCHROEDER JW, SORENSON RJ, SHOWALTER HD, SIMMONS LA 2014 RecO and RecR are necessary for RecA loading in response to DNA damage and replication fork stress. J Bacteriol 196:2851-2860.

https://doi.org/10.1128/JB.01494-14

5. CARRASCO B, SERRANO E, SÁNCHEZ H, WYMAN C, ALONSO JC 2016 Chromosomal transformation in Bacillus subtilis is a non-polar recombination reaction.Nucleic Acids Res 44:2754-2768. https://doi.org/10.1093/nar/gkv1546

6. MIJAKOVIC I, PETRANOVIC D, MACEK B, CEPO T, MANN M, DAVIES J, JENSEN PR, VUJAKLIJA D 2006 Bacterial singlestranded DNA-binding proteins are phosphorylated on tyrosine. Nucleic Acids Res 34:1588-1596.

https://doi.org/10.1093/nar/gkj514

7. PETRANOVIC D, MICHELSEN O, ZAHRADKA K, SILVAC, PETRANOVIC M, JENSEN PR, MIJAKOVIC I 2007 Bacillus subtilis strain deficient for the protein-tyrosine kinase PtkA exhibits impaired DNA replication. Mol Microbiol 63:1797-1805. https://doi.org/10.1111/j.1365-2958.2007.05625.x

8. ELSHOLZ AK, TURGAY K, MICHALIK S, HESSLING B, GRONAU K, OERTEL D, MÄDER U, BERNHARDT J, BECHER D, HECKER M, GERTH U 2012 Global impact of protein arginine phosphorylation on the physiology of Bacillus subtilis. Proc Natl Acad Sci U S A 109:7451-7456.

https://doi.org/10.1073/pnas.1117483109

9. VUJAKLIJA D, MACEK B 2012 Detecting posttranslational modifications of bacterial SSB proteins. Methods Mol Biol 922:205-218. https://doi.org/10.1007/978-1-62703-032-8_16

10. MIJAKOVIC I, DEUTSCHER J 2015 Protein-tyrosine phosphorylation in Bacillus subtilis: a 10-year retrospective. Front Microbiol 6:18. https://doi.org/10.3389/fmicb.2015.00018

11. LIBBY EA, GOSS LA, DWORKIN J 2015 The Eukaryotic-Like Ser/Thr Kinase PrkC Regulates the Essential WalRK Two-Component System in Bacillus subtilis. PLoS Genet 11:e1005275. https://doi.org/10.1371/journal.pgen.1005275
12. BIDNENKO V, SHI L, KOBIR A, VENTROUX M, PIGEONNEAU N, HENRY C, TRUBUIL A, NOIROT-GROS MF, MIJAKOVIC I 2013 Bacillus subtilis serine/threonine protein kinase YabT is involved in spore development via phosphorylation of a bacterial recombinase. Mol Microbiol 88:921-935. https://doi.org/10.1111/mmi.12233

13. KOBIR A, PONCET S, BIDNENKO V, DELUMEAU O, JERS C, ZOUHIR S, GRENHA R, NESSLER S, NOIROT P, MIJAKOVIC I 2014 Phosphorylation of Bacillus subtilis gene regulator AbrB modulates its DNA-binding properties. Mol Microbiol 92:1129-1141. https://doi.org/10.1111/mmi.12617

14. SHI L, PIGEONNEAU N, RAVIKUMAR V, DOBRINIC P, MACEK B, FRANJEVIC D, NOIROT-GROS MF, MIJAKOVIC I 2014 Cross-phosphorylation of bacterial serine/threonine and tyrosine protein kinases on key regulatory residues. Front Microbiol 5:495. https://doi.org/10.3389/fmicb.2014.00495

15. MIJAKOVIC I, GRANGEASSE C, TURGAY K 2016 Exploring the diversity of protein modifications: special bacterial phosphorylation systems. FEMS Microbiol Rev 40:398-417. https://doi.org/10.1093/femsre/fuw003

16. MIJAKOVIC I, PONCET S, BOËL G, MAZÉ A, GILLET S, JAMET E, DECOTTIGNIES P, GRANGEASSE C, DOUBLET P, LE MARÉCHAL P, DEUTSCHER J 2003 Transmembrane modulator-dependent bacterial tyrosine kinase activates UDPglucose dehydrogenases. EMBO J 22:4709-4718. https://doi.org/10.1093/emboj/cdg458

17. CREIXELL P, SCHOOF EM, TAN CS, LINDING R $2012 \mathrm{Mu}-$ tational properties of amino acid residues: implications for evolvability of phosphorylatable residues. Philos Trans R Soc Lond B Biol Sci 367:2584-2593. https://doi.org/10.1098/rstb.2012.0076

18. MEYER R, LAINE PS 1990 The single-stranded DNA-binding protein of Escherichia coli. Microbiol Rev 54:342-380.

19. BOBST EV, PERRINO FW, MEYER RR, Bobst AM 1991 An EPR study to determine the relative nucleic acid binding affinity of singlestranded DNA-binding protein from Escherichia coli. Biochim Biophys Acta 1078: 199-207. https://doi.org/10.1016/0167-4838(91)99010-P

20. GREEN M, HATTER L, BROOKES E, SOULTANAS P, SCOTT DJ 2016 Defining the Intrinsically Disordered C-Terminal Domain of SSB Reveals DNA-Mediated Compaction. J Mol Biol 428:357-364. https://doi.org/10.1016/j.jmb.2015.12.007 